\title{
Detoxification enzymes: cellular metabolism and susceptibility to various diseases
}

Marcelo Silva ${ }^{1}$

(D) Maria da Gloria Carvalho

1 Hospital Universitário Clementino Fraga Filho

\section{DETOXIFICATION ENZYMES}

Detoxification enzymes act in the cellular metabolism of substances that are strange to the organism (xenobiotic) and endogenous compounds that could cause cellular and tissue damage, such as compounds derived from the oxidative stress. Cellular metabolism occurs in three successive phases: in phase 1, potentially toxic compounds are activated, especially through the action of $P$-oxidases cytochrome (CYP) enzymes. ${ }^{1}$ In phase 2 , the compounds that were activated in the previous phase are conjugated to substances that will make them more water soluble and easily excreted. In this phase, glutathione S-transferase (GSTs), UDP-glucuronosyltransferases (UGT), Sulfotransferases (SULT) and N- acetyl-transferase (NAT) enzymes are the main players. ${ }^{2}$ In phase 3 , conjugates compounds are eliminated extracellularly through membrane transporters, which are proteins with ion and molecule transport function through the cellular membrane. ${ }^{3}$ Figure 1 shows a scheme of the cellular metabolism by the action of detoxification enzymes.

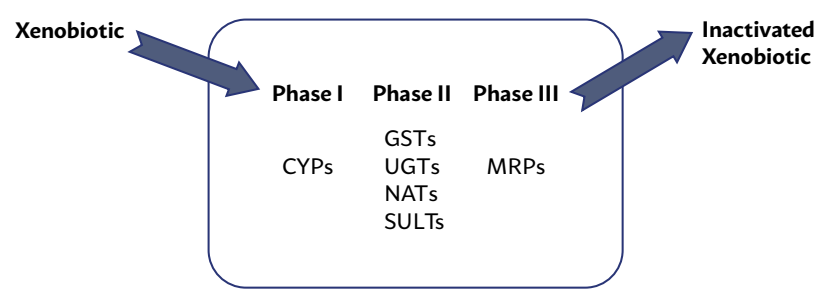

FIGURE 1 Scheme of cellular metabolism by the action of detoxification enzymes. Author: Marcelo S. M. Silva

\section{DETOXIFICATION GENES AND GENETIC POLYMORPHISMS}

Detoxification enzymes are proteins produced from the expression of detoxification genes. By default, the gene receives the same acronym of the protein coded by it, however it is written in italic. Polymorphisms in detoxification genes may affect the function of enzymes coded by them, and conse-

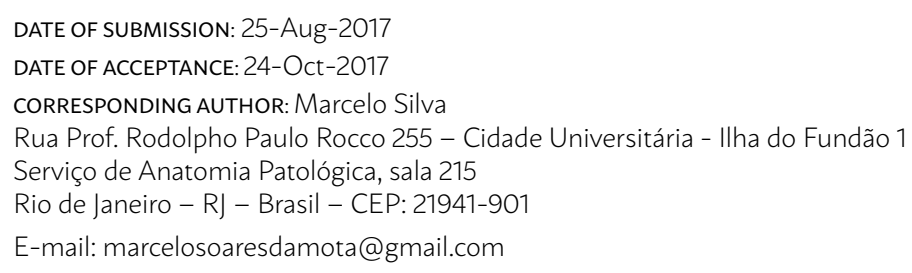


quently, the cellular metabolism. Genetic polymorphisms are alterations in the DNA sequence that can increase the organism susceptibility to develop certain diseases. Polymorphisms characterized by the complete deletion of a gene eliminate any functional activity of the enzyme coded by it. On the other hand, polymorphisms that are duplications of a whole gene may result in higher levels of enzymatic activity. ${ }^{4}$ There are also replacements of amino acids that originate from the single-nucleotide polymorphisms, better known by the acronym SNPs. If the polymorphism is located within the coding region of a gene, there may be the replacement of amino acids in the coded peptide, resulting in protein alterations that may affect the cellular metabolism. An example of that is a single-nucleotide polymorphism that occurs in the apolipoprotein $\mathrm{E}$ gene and that is associated with a higher risk for Alzheimer's disease. ${ }^{5}$

\section{POLYMORPHISMS STUDY METHODS}

Genetic polymorphisms can be studied through several methods, such as PCR (Polymerase Chain Reaction) DNA amplification, followed by agarose or polyacrylamide gel electrophoresis; DNA sequencing; PCR amplification associated with the use of restriction enzymes (this technique is especially used for SNPs investigation), among other methods. In
Figure 2 some methods used for the study of genetic polymorphisms are schematized.

\section{ENVIRONMENTAL FACTORS AND DETOXIFICATION ENZYMES}

Environmental factors are biological or non-biological factors found in the environment that affect living organisms. Among the biological factors are the microorganisms, parasites, food consumed, among others. With relation to the non-biological factors (also known as abiotic), there are air and water industrial pollutants, solar radiation, environment temperature, air humidity, etc. In this context, it is important to consider air pollution and its consequence to the populations' health. Both pollution produced by industrial activities and the burning of fuel by transport vehicles, among others, release a variety of toxic compounds in the air. Respiratory diseases, allergies, increased cases of several types of cancer and cardiovascular diseases are among the main health issues that may be caused by the combustion of petroleum products. Among the compounds generated are the nitrogen oxides, particulate matter and ozone. ${ }^{6}$

The influence of environmental factors in the aetiology of several diseases is well known, especially through epidemiologic studies that count on expres-

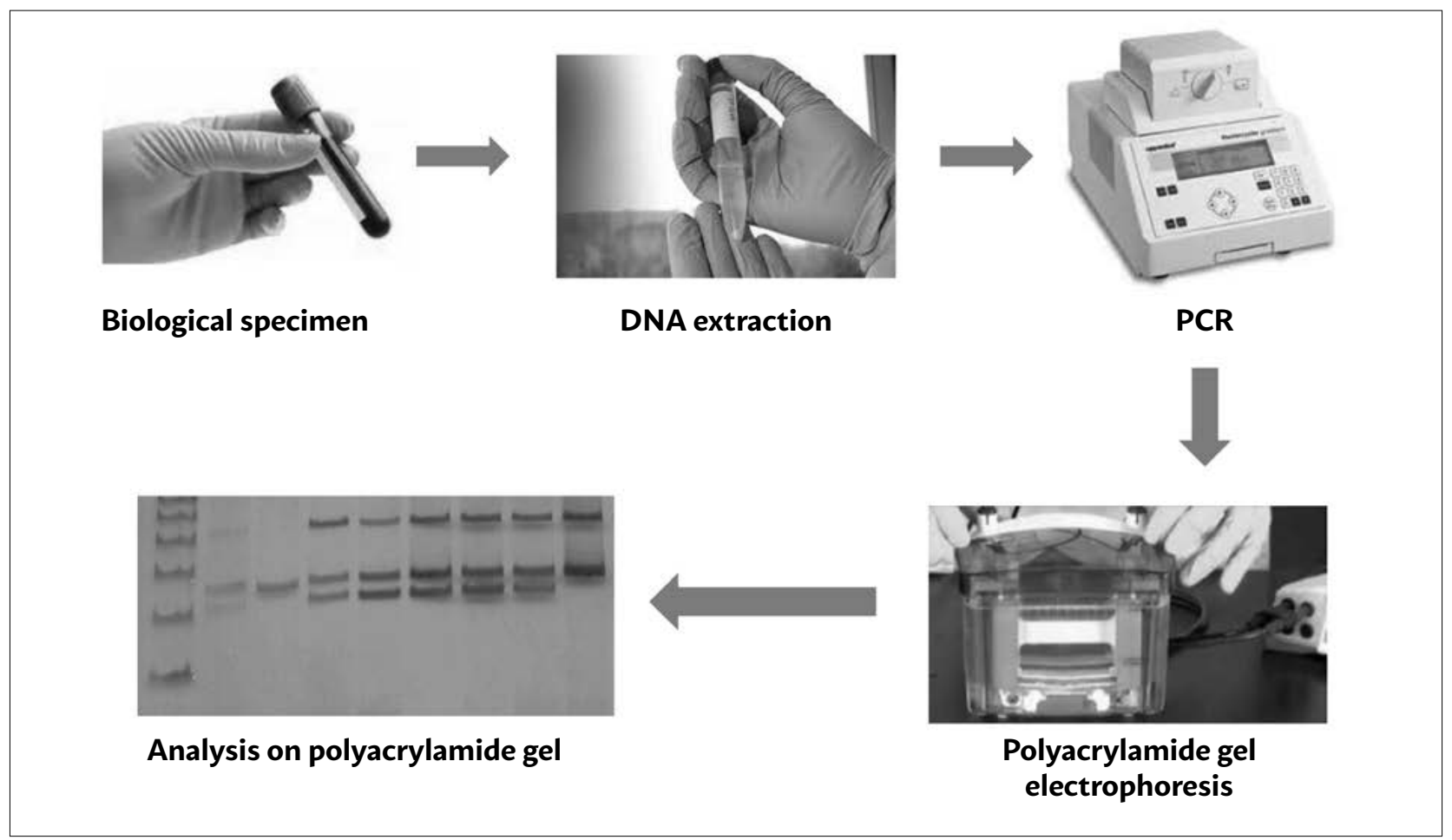

FIGURE 2 Methods of studying genetic polymorphisms. Author: Marcelo S. M. Silva 

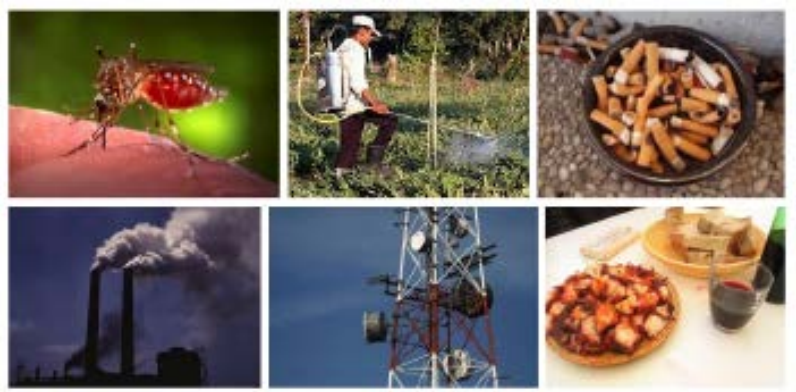

FIGURE 3 Environmental factors that influence human health. Author: Marcelo S. M. Silva

sive numbers of participants, minimizing possible experimental biases. It can be mentioned as example the association between smoking and lung cancer., The close relation between the presence of certain environmental factors and the development of malignant tumours highlights the importance of detoxification enzymes that act to minimize potential damages to the organism. In addition to malignant neoplasia, many other pathologies have been associated to the influence of environmental factors, such as inflammatory bowel disease, respiratory diseases, food poisoning, pesticide poisoning and occupational illnesses. An example of labour disease caused by environmental factor is the green tobacco sickness, which is an acute nicotine poisoning caused by the farmers skin contact with tobacco leaves. ${ }^{9}$ Figure 3 shows some environmental factors that affect human health.

The association between detoxification enzymes alterations and the development of some diseases has been investigated in scientific papers. A case-control study carried out in the city of Goiânia with 100 individuals with glaucoma and 52 healthy controls found $84 \%$ of a single-nucleotide polymorphism in gene CYP1A1 (P-oxidase cytochrome A 1) in the glaucoma patients and $46 \%$ in healthy individuals. ${ }^{10}$ The absence of GSTT1 (glutathione S-transferase theta 1) expression. has been associated in scientific literature with the risk of bladder, ${ }^{11}$ oral cavity ${ }^{12}$ and lung cancers. ${ }^{13} \mathrm{~A}$ case-control study with 98 participants carried out in Southern Brasil showed the association between the GSTM1 (glutathione S-transferase mi 1) deletion and the occurrence of breast cancer. ${ }^{14} \mathrm{~A}$ meta-analysis of 23 studies, including 4,065 cases and 5,390 controls, suggested that the GSTT1 null genotype is associated with the risk of lung cancer in Asian population..$^{15}$ Another meta-analysis including 26,666 cases and 37,210 controls of several ethnicities in different continents suggested that GSTT1 null genotype is significantly associated with an increased risk of urinary system cancer. ${ }^{16}$ An Indian case-control study with 540 participants reported that the GSTM1 deletion is a decisive risk factor for lung cancer in Northern India population. ${ }^{17} \mathrm{~A}$ meta-analysis with 16 studies, including 3,366 patients and 6,013 controls showed that GSTT1 null genotype is significantly associated $(p<0.001)$ with an increased susceptibility to inflammatory bowel disease..$^{18} \mathrm{~A}$ case-control study carried out in South Africa with 202 participants (102 cases and 100 controls) reported association between polymorphisms in genes GSTM1 and GSTP1 and coronary artery disease in the studied population. $^{19}$

\section{IMPLICATIONS IN THE DEVELOPMENT OF CANCER AND CHEMORESISTANCE}

Articles in scientific literature have addressed the role of detoxification enzymes in chemoresistance..$^{20,21}$ For the organism, chemotherapy drugs are xenobiotics and, therefore, must be metabolized and eliminated from the cell. Scientific evidence has established the importance, especially of GSTs, in the patient's response with cancer to the use of chemotherapy. These enzymes are able to metabolize and inactivate anti-cancer agents. ${ }^{21}$ GSTP (glutathione S-transferase pi) class is the most abundantly expressed in human cancer and many solid tumours ${ }^{22}$ and leukaemia; the high expression of GSTP1 has been associated with chemoresistance, treatment failure and low survival rate of patients. ${ }^{21}$

\section{CONCLUSION}

The relevance of detoxification enzymes in processes connected to the metabolism of toxic substances has been confirmed through scientific investigation. The functioning of these enzymes can influence susceptibility to many diseases, as well as resistance to drugs. This knowledge highlights the importance of seeking better understanding, through different types of studies (case-control, meta-analysis, biochemical studies, etc.) of the interaction between environmental factors, detoxification enzymes and health condition of individuals and populations. 
PALAVRAS-CHAVE: Predisposição genética para doença. Suscetibilidade a doenças. Glutationa S-Transferase pi. Enzimas. Polimorfismo genético.

\section{REFERENCES}

1. Nebert DW, Dalton TP. The role of cytochrome P450 enzymes in endogenous signaling pathways and environmental carcinogenesis. Nat Rev Cancer. 2006;6(12):947-60

2. Jancova P, Anzenbacher P, Anzenbacherova E. Phase II drug metabolizing enzymes. Biomed Pap Med Fac Univ Palacky Olomouc Czech Repub. 2010;154(2):103-16.

3. Omiecinski C|, Vanden Heuvel IP, Perdew GH, Peters |M. Xenobiotic metabolism, disposition, and regulation by receptors: from biochemical phenomenon to predictors of major toxicities. Toxicol Sci. 2011;120(Suppl 1):S49-75.

4. Miller MC $3^{\text {rd }}$, Mohrenweiser HW, Bell DA. Genetic variability in susceptibility and response to toxicants. Toxicol Lett. 2001;120(1-3):269-80.

5. Wolf $A B$, Caselli RJ, Reiman EM, Valla J. APOE and neuroenergetics: an emerging paradigm in Alzheimer's disease. Neurobiol Aging. 2013;34(4):1007-17.

6. Yang IA, Fong KM, Zimmerman PV, Holgate ST, Holloway JW. Genetic susceptibility to the respiratory effects of air pollution. Thorax. 2008;63(6):555-63.

7. Carlsten C, Sagoo GS, Frodsham AJ, Burke W, Higgins JP. Glutathione S-transferase M1 (GSTM1) polymorphisms and lung cancer: a literature-based systematic HuGE review and meta-analysis. Am J Epidemiol. 2008;167(7):759-74.

8. Danaei G, Vander Hoorn S, Lopez AD, Murray C), Ezzati M; Comparative Risk Assessment collaborating group (Cancers). Causes of cancer in the world: comparative risk assessment of nine behavioral and environmental risk factors. Lancet. 2005;366(9499):1784-93.

9. Bartholomay P, Iser BP, Oliveira PP, Santos TE, Malta DC, Sobel J, et al. Epidemiologic investigation of an occupational illness of tobacco harvesters in southern Brazil, a worldwide leader in tobacco production. Occup Environ Med. 2012;69(7):514-8.

10. Costa NB, Silva CT, Frare AB, Silva RE, Moura KK. Association between CYP1A1m1 gene polymorphism and primary open-angle glaucoma. Genet Mol Res. 2014;13(4):10382-9.

11. Srivastava DS, Kumar A, Mittal B, Mittal RD. Polymorphism of GSTM1 and GSTT1 genes in bladder cancer: a study from North India. Arch Toxicol. 2004;78(8):430-4
12. Sreelekha TT, Ramadas $K$, Pandey M, Thomas G, Nalinakumari KR, Pillai MR. Genetic polymorphism of CYP1A1, GSTM1 and GSTT1 genes in Indian oral cancer. Oral Oncol. 2001;37(7):593-8.

13. Hosgood HD $3^{\text {rd }}$, Berndt SI, Lan Q. GST genotypes and lung cancer susceptibility in Asian populations with indoor air pollution exposures: a meta-analysis. Mutat Res. 2007;636(1-3):134-43.

14. Possuelo LG, Peraça CF, Eisenhardt MF, Dott ML, Cappelletti L, Folleto E, et al. Polymorphisms of GSTM1 and GSTT1 genes in breast cancer susceptibility: a case-control study. Rev Bras Ginecol Obstet. 2013;35(12):569-74.

15. Yang X, Qiu MT, Hu JW, Wang XX, Jiang F, Yin R, et al. GSTT1 null genotype contributes to lung cancer risk in Asian populations: a meta-analysis of 23 studies. PLoS One. 2013;8(4):e62181.

16. Wang $Y, H e$ I, Ma TI, Lei W, Li F, Shen H, et al. GSTT1 null genotype significantly increases the susceptibility to urinary system cancer: evidences from 63,876 subjects. J Cancer. 2016;7(12):1680-93.

17. Sharma N, Singh A, Singh N, Behera D, Sharma S. Genetic polymorphisms in GSTM1, GSTT1 and GSTP1 genes and risk of lung cancer in a North Indian population. Cancer Epidemiol. 2015;39(6):947-55.

18. Qian J, Song Z, Lv Y, Huang X, Mao B. Glutathione S-transferase T1 null genotype is associated with susceptibility to inflammatory bowel disease. Cell Physiol Biochem. 2017;41(6):2545-52.

19. Phulukdaree A, Khan S, Moodley D, Chuturgoon AA. GST polymorphisms and early-onset coronary artery disease in young South African Indians. S Afr Med ). 2012;102(7):627-30.

20. Traverso N, Ricciarelli R, Nitti M, Marengo B, Furfaro AL, Pronzato MA, et al. Role of glutathione in cancer progression and chemoresistance. Oxid Med Cell Longev. 2013;2013:972913.

21. Lo HW, Ali-Osman F. Genetic polymorphism and function of glutathione S-transferases in tumor drug resistance. Curr Opin Pharmacol. 2007;7(4):367-74.

22. Tew KD Manevich $Y$, Grek $C$, Xiong $Y$, Uys I, Townsend DM. The role of glutathione $S$-transferase $P$ in signaling pathways and $S$-glutathionylation in cancer. Free Radic Biol Med. 2011;51(2):299-313. 